This is the author's version of the work. It is posted here by permission of the AAAS for personal use, not for redistribution. The definitive version was published in Science,

http://science.sciencemag.org/content/360/6395/1355 (2018-06-21), doi: 110.1126/science.aar5273.

2

3

4

5

\title{
Title: Adaptive Introgression Underlies Polymorphic Seasonal Camouflage in Snowshoe Hares
}

Authors: Matthew R. Jones ${ }^{1 *}$, L. Scott Mills ${ }^{2,3,4}$, Paulo Célio Alves ${ }^{2,5,6}$, Colin M. Callahan ${ }^{1}$, Joel M. Alves ${ }^{5,7}$, Diana J. R. Lafferty ${ }^{2,4,8}$, Francis M. Jiggins ${ }^{7}$, Jeffrey D. Jensen ${ }^{9,10}$, José MeloFerreira $^{5,6^{*}}$, Jeffrey M. Good ${ }^{1,2^{*}}$

\section{Affiliations:}

$8 \quad{ }^{1}$ Division of Biological Sciences, University of Montana, Missoula, MT 59812, USA.

${ }^{2}$ Wildlife Biology Program, University of Montana, Missoula, MT 59812, USA.

${ }^{3}$ Office of Research and Creative Scholarship, University of Montana, Missoula, MT 59812, USA.

${ }^{4}$ Fisheries, Wildlife, and Conservation Biology Program, Department of Forestry and Environmental Resources, North Carolina State University, Raleigh, NC 27695, USA.

${ }^{5} \mathrm{CIBIO}$, Centro de Investigação em Biodiversidade e Recursos Genéticos, InBIO Laboratório Associado, Universidade do Porto, 4485-661 Vairão, Portugal.

${ }^{6}$ Departamento de Biologia, Faculdade de Ciências da Universidade do Porto, 4169-007 Porto, Portugal.

${ }^{7}$ Department of Genetics, University of Cambridge, Cambridge CB2 3EH, UK.

${ }^{8}$ Department of Biology, Northern Michigan University, Marquette, MI 49855, USA.

${ }^{9}$ School of Life Sciences, Ecole Polytechnique Fédérale de Lausanne, 1015 Lausanne,

Switzerland.

$22{ }^{10}$ School of Life Sciences, Arizona State University, Tempe, AZ 85281, USA.

*Correspondence to: matthew2.jones@umontana.edu,jmeloferreira@cibio.up.pt, jeffrey.good@umontana.edu 
26 Abstract: Snowshoe hares (Lepus americanus) maintain seasonal camouflage by molting to a 27 white winter coat, but in regions with low snow cover some hares remain brown in the winter.

28 We show that cis-regulatory variation controlling seasonal expression of the Agouti gene

29 underlies this adaptive winter camouflage polymorphism. Genetic variation at Agouti clustered

30 by winter coat color across multiple hare and jackrabbit species, revealing a history of recurrent

31 interspecific gene flow. Brown winter coats in snowshoe hares originated from an introgressed

32 black-tailed jackrabbit allele that has swept to high frequency in mild winter environments.

33 These discoveries show that exchange of genetic variants underlying key ecological traits

34 through hybridization can seed past and ongoing adaptation to rapidly changing environments.

36 One Sentence Summary: Introgression at the pigmentation gene Agouti underlies local

37 adaptation in seasonal camouflage of snowshoe hares. 
Main Text: Many species undergo reversible changes in morphology, physiology, and behavior to cope with the challenges of seasonal environments. These critical components of phenotypic

40 plasticity often track the environment through the photoperiod-dependent release of hormones

41 (1). However, circannual rhythms can become desynchronized when abiotic conditions change

42 rapidly (2), leading to declines in population fitness (3). The capacity of species to adapt to

43 rapidly changing environments will depend in part on the proximate and ultimate causes of

44 variation underlying seasonal traits $(4,5)$, which remain poorly understood at the molecular level $45(1,2)$.

At least 21 bird and mammal species undergo autumn molts from brown to white coats

$47(6,7)$ as part of a suite of plastic trait responses to seasonal environments. We used natural

48 variation in seasonal camouflage of the snowshoe hare (Lepus americanus) to understand the

49 genetic basis of this critical seasonal trait. Autumn molts to white winter coats are cued by

50 photoperiod (8) and generally track seasonal snow cover. Direct estimates of hare survival have

51 shown that mismatch between coat color and snow cover increases predation (3). White winter

52 coats predominate across the snowshoe hare range, but some populations molt into brown winter coats (Fig. 1). In the Pacific Northwest (PNW), shifts in the probability of white coats coincide with a gradient in snow cover from warmer coastal to colder inland environments, consistent with local selection for seasonal camouflage with color morphs co-occurring across a broad polymorphic zone (Fig. 1C) (7).

To dissect the genetic basis of polymorphic seasonal camouflage, we used whole genome sequences for a winter-white hare from Montana (MT, 33× coverage) $(9,10)$ and a winter-brown hare from Washington (WA, $22 \times$ coverage) and constructed a reference through iterative mapping $(11)$ to the rabbit genome $(9,12)$. We then sequenced 80 whole exomes $(62 \mathrm{Mb}, 21 \times \pm$ 
617.6 per individual) from two regions in the PNW polymorphic zone (WA: $n=26$, Oregon

62 hereafter OR: $n=26$, each region $50 \%$ winter-white), a monomorphic winter-white locality in MT

$63(n=14)$, and a monomorphic winter-brown locality in British Columbia (BC: $n=14$; table S1). If

64 the polymorphic zone represents admixture between previously isolated populations, then

65 genetic structure could obscure genotype-phenotype associations (13). Analysis of 38,694

66 unlinked single nucleotide polymorphisms (SNPs) revealed geographic structure (Fig. 1C), but

67 genome-wide genetic differentiation $\left(F_{\mathrm{ST}}\right)$ between winter-brown and winter-white individuals

68 was $\sim 0$ within polymorphic localities (table S2). The polymorphic zone also showed no evidence

69 of admixture based on patterns of linkage disequilibrium (fig. S1) or allele sharing with other

70 populations (table S3) (14). Thus, geographic variation for winter coat color in the PNW likely

71 reflects primary intergradation across a gradient in snow cover.

We tested 513,812 SNPs for coat color associations across polymorphic populations and identified a single outlier region on chromosome 4 in perfect association with winter coat color $\left(P=4.24 \times 10^{-10} ;\right.$ Fig. 2 A, fig. S2, Additional Data table S1) (12). We then augmented exome data with low-coverage whole genome resequencing of polymorphic zone hares $(\sim 20 \times$ per color morph). Coat color associations based on genotype likelihoods $(15,173,804$ SNPs) (15) confirmed a single outlier region (fig. S3) localized to a $\sim 225$ kilobase $(\mathrm{kb})$ interval of elevated $F_{\mathrm{ST}}$ between color morphs centered on the pigmentation gene Agouti and two flanking genes, Ahcy and Eif2s2 (Fig. 2B). Winter-brown hares were homozygous ( $n=26)$ for brown-associated alleles (hereafter, $a$ ), while winter-white hares were either heterozygous $(n=24)$ or homozygous

$81(n=2)$ for the alternative allele (hereafter, $A$; Fig. 2 C). We then induced autumn molts in 18 82 captive wild-caught hares (WA: $n=11, \mathrm{MT}: n=7$ ) and found perfect concordance between Agouti genotypes and winter coat colors (Fig. 2C, table S4). This experiment included a heterozygous 
(Aa) wild-caught pregnant winter-white female from WA that gave birth in captivity to both winter-white and winter-brown offspring (Fig. 2D). Therefore, winter coat color segregates as a dominant locus in both wild and captive animals.

The agouti signaling protein (ASIP) antagonizes the melanocortin-1 receptor (MC1R) in follicular melanocytes, shifting melanogenesis towards lighter pheomelanin pigments or inhibiting pigment production (16). MC1R mutations suppress expression of winter-white coats in dark or blue color morphs of arctic foxes, suggesting that ASIP-MC1R interactions are involved in the development of seasonal color molts (17). Agouti is typically expressed as ventral or hair cycle-specific isoforms distinguished by alternative 5' untranslated regions (UTRs, Fig. 2B) (18). Both isoforms have been associated with lighter dorsal pelage $(19,20)$. We hypothesized that the development of winter-white coats, which mostly lack pigments $(8)$, is controlled by isoform-specific upregulation of Agouti during the autumn molt. To test this, we quantified allele-specific expression of both isoforms and the closely linked Ahcy locus in dorsal skin biopsies from three captive heterozygous hares $(A a)$ undergoing brown-to-white molts. Quantitative PCR verified expression of Ahcy and the Agouti hair-cycle isoform while expression of the ventral isoform was negligible (Fig. 3A, table S5, table S6). Targeted pyrosequencing revealed highly skewed expression toward the white $(A)$ allele of the hair-cycle Agouti isoform $(P<0.0001$, Student's t-test), indicative of $c i s$-regulatory variation, while Ahcy showed equal allelic expression (Fig. 3B, table S7). These data suggest that winter-white coats develop as a consequence of increased expression of Agouti during the autumn molt, which fits with our observed dominance relationships and previous studies on the evolution of lighter pelage in deer mice $(19,20)$. Our findings directly link Agouti expression and the evolution of seasonal 
camouflage in snowshoe hares and suggest that cis-regulatory evolution plays an important role

107 in the origin of novel seasonal traits.

108 Comparison of winter-white (MT) and winter-brown genomes (WA) revealed

109 extraordinarily elevated levels of absolute genetic divergence across Agouti $\left(\right.$ Agouti $d_{X Y}=1.6 \%$;

110 genome-wide $d_{X Y}=0.41 \%$; bootstrapped $P<0.0001$; Fig. 4 A, fig. S4), indicating that the color

111 polymorphism did not arise from a recent de novo mutation. Alternatively, elevated divergence

112 could reflect either the long-term maintenance of polymorphism or introgression from another

113 species $(21,22)$. Six of the 32 species of hares and jackrabbits (genus Lepus) have winter-white

114 molts but evolutionary relationships within this rapid radiation are poorly resolved (23). To

115 examine the origins of winter coat color variants, we combined whole genome sequences of two

116 additional winter-white snowshoe hares from Pennsylvania (PA) and Utah (UT), two winter-

117 brown black-tailed jackrabbits (L. californicus) from Nevada, and a previously sequenced

118 winter-white mountain hare (L. timidus) from Europe (10). Phylogenetic analyses (24) predicted

119 an exceptionally rare topology at Agouti that clustered individuals by winter coat color (Fig. 4B,

120 fig. S5B). Pairwise divergence between all winter-brown and white individuals was significantly

121 elevated across a known cis-regulatory region of $\operatorname{Agouti}(25,26) \sim 40 \mathrm{~kb}$ upstream of the

122 transcription start site of the hair-cycle isoform $(P<0.001$; Fig. 4A, fig. S4). Divergence peaked

123 across a $\sim 20 \mathrm{~kb}$ interval $\left(d_{X Y}=2.2-2.4 \%\right)$ that included a 1,033 base pair insertion on the winter-

124 white haplotype and a $\sim 4.3 \mathrm{~kb}$ deletion on the winter-brown haplotype (fig. S4). Additional

125 functional data are needed to determine if either of these candidate mutations underlie the

126 observed cis-regulatory differences in Agouti expression (Fig. 3B).

127 The elevated interspecific divergence between color groups suggests that the winter-

128 white and brown Agouti alleles may have arisen relatively early in Lepus (21). In contrast, 
129 divergence within color groups was strongly reduced across a larger interval encompassing

130 Agouti (Fig. 4A, fig. S6), indicating that winter coat color alleles may have been shared through

131 hybridization. In support of this hypothesis, we found low but significant levels of genome-wide

132 introgression (27) between snowshoe hares and both black-tailed jackrabbits and mountain hares

133 (table S8). Window-based analyses of absolute divergence and derived allele sharing (28)

134 identified Agouti among the strongest genome-wide signatures of introgression in both winter-

135 brown and winter-white clusters (fig. S7).

136 Previous studies demonstrated mitochondrial DNA introgression from black-tailed

137 jackrabbits, a western North American prairie-scrub species, into PNW snowshoe hares and

138 speculated that hybridization may have contributed to the evolution of brown winter coats in

139 snowshoe hares $(29,30)$. Consistent with this, winter-brown snowshoe hares unambiguously

140 nested within black-tailed jackrabbit variation at Agouti (Fig. 4B, fig. S5B) resulting in a $174 \mathrm{~kb}$

141 interval of significantly reduced divergence between species $\left(d_{X Y}=0.42 \%\right.$ versus $1.2 \%$ genome-

142 wide) embedded within a $236 \mathrm{~kb}$ interval of significantly elevated admixture proportions

$143\left(\hat{f}_{\text {hom }}=0.71 ;\right.$ Fig. $\left.4 \mathrm{~A}\right)$. Strong selection at a locus in the ancestral population can reduce

144 divergence between species (31), resulting in false inferences of admixture (28); however,

145 coalescent simulations of shared polymorphism with and without selection in the ancestral

146 population indicate that such a long interval of shallow divergence is highly unlikely in the

147 absence of interspecific gene flow (Fig. 4C, fig. S7, fig. S8). We also detected introgression

148 within the winter-white Agouti group (fig. S7, fig. S8). Resolving the origin and functional

149 relevance of these signatures awaits further investigation given that three other North American

150 Lepus species undergo some degree of seasonal coat color change (7). 
To link introgression with local adaptation we tested for selective sweeps based on allele

152 frequency skews (32) while controlling for demographic history (fig. S9, table S9). We detected

153 a hard sweep overlapping Agouti in winter-brown individuals from the polymorphic zone, but no

154 evidence for a sweep in winter-white individuals (fig. S10, fig. S11). We estimate that the sweep

155 of the winter-brown allele in the PNW occurred 3-15 kya, following the retreat of the Cordilleran

156 ice sheet (33). High inferred selection coefficients $(s)$ on the introgressed winter-brown Agouti

157 background $\left(\bar{s}_{W A}=0.024, \bar{s}_{O R}=0.015\right.$; fig. S11C) and fixation of alternative Agouti alleles between

158 monomorphic winter-brown (BC) and winter-white (MT) localities (Fig. 4D), despite high gene

159 flow (table S9), indicate that seasonal camouflage is maintained under strong local selection.

160 Despite widespread evidence of hybridization between animal species, introgression has

161 rarely been directly linked to ecological adaptation (34-36). We have shown that introgression

162 has shaped locally adaptive seasonal camouflage in snowshoe hares. Recurrent introgression of

163 coat color variants could facilitate evolutionary responses to environmental change within

164 populations as well as the long-term maintenance of adaptive variation among species, similar to

165 adaptive polymorphisms in beak morphology across the radiation of Darwin's finches $(22,34)$.

166 Introgression of winter-brown coats into snowshoe hares may have enabled their persistence in

167 environments with more ephemeral seasonal snow following the end of the last glacial

168 maximum. Temperate snow cover duration is predicted to dramatically decrease over the next

169 century under most models of climate change (37), which may further intensify directional

170 selection for winter-brown camouflage $(3,6)$. Thus, the recent establishment of this dynamic

171 color polymorphism through introgression is likely to be a critical component of ongoing

172 adaptation to rapidly changing seas onal environments (7) in this iconic ecological model. 


\section{References and Notes:}

174 1. M. E. Visser, S. P. Caro, K. van Oers, S. V. Schaper, B. Helm, Phenology, seasonal timing 175 and circannual rhythms: towards a unified framework. Philos. Trans. Biol. Sci. 365, 3113$176 \quad 3127(2010)$.

177 2. B. Helm, R. Ben-Shlomo, M. J. Sheriff, R. A. Hut., R. Foster, B. M. Barnes, D.

178 Dominoni, Annual rhythms that underlie phenology: biological time-keeping meets 179 environmental change. Proc. R. Soc. B Biol. Sci. 280, 20130016 (2013).

180 3. M. Zimova, L. S. Mills, J. J. Nowak, High fitness costs of climate change-induced $181 \quad$ camouflage mismatch. Ecol. Lett. 19, 299-307 (2016).

182 4. W. E. Bradshaw, C. M. Holzapfel, Genetic response to rapid climate change: it's seasonal 183 timing that matters. Mol. Ecol. 17, 157-166 (2008).

184 5. A. A. Hoffmann, C. M. Sgrò, Climate change and evolutionary adaptation. Nature. 470, $185 \quad 479-485(2011)$.

186 6. L. S. Mills, M. Zimova, J. Oyler, S. Running, J. T. Abatzoglou, P. M. Lukacs, Camouflage 187 mismatch in seasonal coat color due to decreased snow duration. Proc. Natl. Acad. Sci. U. S. A. 110, 7360-7365 (2013).

189 7. L. S. Mills, E. V Bragina, A. V Kumar, M. Zimova, D. J. R. Lafferty, J. Feltner, B. M. Davis, K. Hackländer, P. C. Alves, J. M. Good, J. Melo-Ferreira, A. Dietz, A. V Abramov, N. Lopatina, K. Fay, Winter color polymorphisms identify global hot spots for evolutionary rescue from climate change. Science. 359, 1033-1036 (2018).

8. C. P. Lyman, Control of coat color in the varying hare Lepus americanus Erxleben. Bull. Museum Comp. Zool. Harvard Coll. 93, 391-461 (1943).

195 9. M. Carneiro, C.-J. Rubin, F. Di Palma, F. W. Albert, J. Alföldi, A. Martinez Barrio, G. 
Pielberg, N. Rafati, S. Sayyab, J. Turner-Maier, S. Younis, S. Afonso, B. Aken, J. M. Alves, D. Barrell, G. Bolet, S. Boucher, H. A. Burbano, R. Campos, J. L. Chang, V. Duranthon, L. Fontanesi, H. Garreau, D. Heiman, J. Johnson, R. G. Mage, Z. Peng, G. Queney, C. Rogel-Gaillard, M. Ruffier, S. Searle, R. Villafuerte, A. Xiong, S. Young, K. Forsberg-Nilsson, J. M. Good, E. S. Lander, N. Ferrand, K. Lindblad-Toh, L. Andersson, Rabbit genome analysis reveals a polygenic basis for phenotypic change during domestication. Science. 345, 1074-1079 (2014).

10. F. Seixas, P. Boursot, J. Melo-Ferreira, The genomic impact of historical hybridization with massive mitochondrial DNA introgression. In review.

11. B. A. J. Sarver, S. Keeble, T. Cosart, P. K. Tucker, M. D. Dean, J. M. Good, Phylogenomic insights into mouse evolution using a pseudoreference approach. Genome Biol. Evol. 9, 726-739 (2017).

12. Materials and methods are available as supplementary materials on Science Online.

13. J. K. Pritchard, M. Stephens, N. A. Rosenberg, P. Donnelly, Association mapping in structured populations. Am. J. Hum. Genet. 67, 170-181 (2000).

14. D. Reich, N. Patterson, D. Campbell, A. Tandon, S. Mazieres, N. Ray, M. V Parra, W. Rojas, C. Duque, N. Mesa, L. F. García, O. Triana, S. Blair, A. Maestre, J. C. Dib, C. M. Bravi, G. Bailliet, D. Corach, T. Hünemeier, M. C. Bortolini, F. M. Salzano, M. L. PetzlErler, V. Acuña-Alonzo, C. Aguilar-Salinas, S. Canizales-Quinteros, T. Tusié-Luna, L. Riba, M. Rodríguez-Cruz, M. Lopez-Alarcón, R. Coral-Vazquez, T. Canto-Cetina, I. Silva-Zolezzi, J. C. Fernandez-Lopez, A. V Contreras, G. Jimenez-Sanchez, M. J. GómezVázquez, J. Molina, A. Carracedo, A. Salas, C. Gallo, G. Poletti, D. B. Witonsky, G. Alkorta-Aranburu, R. I. Sukernik, L. Osipova, S. A. Fedorova, R. Vasquez, M. Villena, C. 
Moreau, R. Barrantes, D. Pauls, L. Excoffier, G. Bedoya, F. Rothhammer, J.-M.

Dugoujon, G. Larrouy, W. Klitz, D. Labuda, J. Kidd, K. Kidd, A. Di Rienzo, N. B. Freimer, A. L. Price, A. Ruiz-Linares, Reconstructing Native American population history. Nature. 488, 370-374 (2012).

15. T. S. Korneliussen, A. Albrechtsen, R. Nielsen, ANGSD: Analysis of Next Generation Sequencing Data. BMC Bioinformatics. 15, 356 (2014).

16. E. Le Pape, T. Passeron, A. Giubellino, J. C. Valencia, R. Wolber, V. J. Hearing, Microarray analysis sheds light on the dedifferentiating role of agouti signal protein in murine melanocytes via the Mc1r. Proc. Natl. Acad. Sci. U. S. A. 106, 1802-1807 (2009).

19. C. R. Linnen, E. P. Kingsley, J. D. Jensen, H. E. Hoekstra, On the origin and spread of an adaptive allele in deer mice. Science. 325, 1095-1098 (2009).

20. M. Manceau, V. S. Domingues, R. Mallarino, H. E. Hoekstra, The developmental role of Agouti in color pattern evolution. Science. 331, 1062-1065 (2011).

21. R. F. Guerrero, M. W. Hahn, Speciation as a sieve for ancestral polymorphism. Mol. Ecol. 26, 5362-5368 (2017).

22. F. Han, S. Lamichhaney, B. R. Grant, P. R. Grant, L. Andersson, M. T. Webster, Gene flow, ancient polymorphism, and ecological adaptation shape the genomic landscape of 
divergence among Darwin's finches. Genome Res. 27, 1004-1015 (2017).

23. J. Melo-Ferreira, P. Boursot, M. Carneiro, P. J. Esteves, L. Farelo, P. C. Alves, Recurrent introgression of mitochondrial DNA among hares (Lepus spp.) revealed by species-tree inference and coalescent simulations. Syst. Biol. 61, 367-381 (2012).

24. N. Zamani, P. Russell, H. Lantz, M. P. Hoeppner, J. R. S. Meadows, N. Vijay, E. Mauceli, F. di Palma, K. Lindblad-Toh, P. Jern, M. G. Grabherr, Unsupervised genome-wide recognition of local relationship patterns. BMC Genomics. 14, 347 (2013).

26. C. R. Linnen, Y.-P. Poh, B. K. Peterson, R. D. H. Barrett, J. G. Larson, J. D. Jensen, H. E. Hoekstra, Adaptive evolution of multiple traits through multiple mutations at a single gene. Science. 339, 1312-1316 (2013).

28. S. H. Martin, J. W. Davey, C. D. Jiggins, Evaluating the use of ABBA-BABA statistics to locate introgressed loci. Mol. Biol. Evol. 32, 244-257 (2015). hare. Mol. Ecol. 23, 2929-2942 (2014).

30. J. Melo-Ferreira, F. A. Seixas, E. Cheng, L. S. Mills, P. C. Alves, The hidden history of the snowshoe hare, Lepus americanus: extensive mitochondrial DNA introgression inferred from multilocus genetic variation. Mol. Ecol. 23, 4617-4630 (2014).

31. T. E. Cruickshank, M. W. Hahn, Reanalysis suggests that genomic islands of speciation 
are due to reduced diversity, not reduced gene flow. Mol. Ecol. 23, 3133-3157 (2014).

266

32. P. Pavlidis, D. Živkovic, A. Stamatakis, N. Alachiotis, SweeD: likelihood-based detection of selective sweeps in thousands of genomes. Mol. Biol. Evol. 30, 2224-2234 (2013).

33. J. J. Clague, T. S. James, History and isostatic effects of the last ice sheet in southern British Columbia. Quat. Sci. Rev. 21, 71-87 (2002).

34. S. Lamichhaney, F. Han, J. Berglund, C. Wang, M. S. Almen, M. T. Webster, B. R. Grant, P. R. Grant, L. Andersson, A beak size locus in Darwin's finches facilitated character displacement during a drought. Science. 352, 470-474 (2016).

35. Y. Song, S. Endepols, N. Klemann, D. Richter, F.-R. Matuschka, C.-H. Shih, M. W. Nachman, M. H. Kohn, Adaptive introgression of anticoagulant rodent poison resistance by hybridization between old world mice. Curr. Biol. 21, 1296-1301 (2011).

36. C. Pardo-Diaz, C. Salazar, S. W. Baxter, C. Merot, W. Figueiredo-Ready, M. Joron, W. O. McMillan, C. D. Jiggins, Adaptive introgression across species boundaries in Heliconius butterflies. PLoS Genet. 8, e1002752 (2012).

37. G. T. Pederson, S. T. Gray, C. A. Woodhouse, J. L. Betancourt, D. B. Fagre, J. S. Littell, E. Watson, B. H. Luckman, L. J. Graumlich, The unusual nature of recent snowpack declines in the North American Cordillera. Science. 333, 332-335 (2011).

38. C. A. Matthee, B. J. Van Vuuren, D. Bell, T. J. Robinson, A molecular supermatrix of the rabbits and hares (Leporidae) allows for the identification of five intercontinental exchanges during the Miocene. Syst. Biol. 53, 433-447 (2004).

39. K. Katoh, D. M. Standley, MAFFT multiple sequence alignment software version 7: improvements in performance and usability. Mol. Biol. Evol. 30, 772-780 (2013).

40. M. R. Jones, J. M. Good, Targeted capture in evolutionary and ecological genomics. Mol. 
Ecol. 25, 185-202 (2016).

289

41. M. S. Ferreira, P. C. Alves, C. M. Callahan, J. P. Marques, L. S. Mills, J. M. Good, J. Melo-Ferreira, The transcriptional landscape of seasonal coat colour moult in the snowshoe hare. Mol. Ecol. 26, 4173-4185 (2017).

42. D. W. Nagorsen, Winter pelage colour in snowshoe hares (Lepus americanus) from the Pacific Northwest. Can. J. Zool. 61, 2313-2318 (1983).

43. W. B. Grange, The pelages and color changes of the snowshoe hare, Lepus americanus phaeonotus, Allen. J. Mammal. 13, 99-116 (1932).

44. M. Meyer, M. Kircher, Illumina sequencing library preparation for highly multiplexed target capture and sequencing. Cold Spring Harb. Protoc. (2010), doi:10.1101/pdb.prot5448.

45. N. Rohland, D. Reich, Cost-effective, high-throughput DNA sequencing libraries for multiplexed target capture. Genome Res. 22, 939-946 (2012).

46. V. A. Trifonov, N. N. Vorobieva, W. Rens, in Fluorescence In Situ Hybridization (FISH) - Application Guide (Springer, Berlin, Heidelberg, 2009), pp. 99-109.

47. A. M. Bolger, M. Lohse, B. Usadel, Trimmomatic: a flexible trimmer for Illumina sequence data. Bioinformatics. 30, 2114-2120 (2014).

48. T. Magoč, S. L. Salzberg, FLASH: fast length adjustment of short reads to improve genome assemblies. Bioinformatics. 27, 2957-2963 (2011).

49. H. Li, Aligning sequence reads, clone sequences and assembly contigs with BWA-MEM (2013) (available at http://arxiv.org/abs/1303.3997).

50. A. McKenna, M. Hanna, E. Banks, A. Sivachenko, K. Cibulskis, A. Kernytsky, K. Garimella, D. Altshuler, S. Gabriel, M. Daly, M. A. DePristo, The Genome Analysis 
Toolkit: A MapReduce framework for analyzing next-generation DNA sequencing data. Genome Res. 20, 1297-1303 (2010).

51. P. Danecek, A. Auton, G. Abecasis, C. A. Albers, E. Banks, M. A. DePristo, R. E.

$$
\text { Handsaker, G. Lunter, G. T. Marth, S. T. Sherry, G. McVean, R. Durbin, The variant call }
$$
format and VCFtools. Bioinformatics. 27, 2156-2158 (2011).

52. E. Han, J. S. Sinsheimer, J. Novembre, Characterizing bias in population genetic inferences from low-coverage sequencing data. Mol. Biol. Evol. 31, 723-735 (2014).

53. H. Li, B. Handsaker, A. Wysoker, T. Fennell, J. Ruan, N. Homer, G. Marth, G. Abecasis, R. Durbin, 1000 Genome Project Data Processing Subgroup, The Sequence Alignment/Map format and SAMtools. Bioinformatics. 25, 2078-2079 (2009).

54. S. Y. Kim, K. E. Lohmueller, A. Albrechtsen, Y. Li, T. Korneliussen, G. Tian, N. Grarup, T. Jiang, G. Andersen, D. Witte, T. Jorgensen, T. Hansen, O. Pedersen, J. Wang, R. Nielsen, Estimation of allele frequency and association mapping using next-generation sequencing data. BMC Bioinformatics. 12, 231 (2011).

55. D. H. Alexander, J. Novembre, K. Lange, Fast model-based estimation of ancestry in unrelated individuals. Genome Res. 19, 1655-1664 (2009).

56. N. Patterson, A. L. Price, D. Reich, Population structure and eigenanalysis. PLoS Genet. 2, e190 (2006).

57. S. R. Browning, B. L. Browning, Rapid and accurate haplotype phasing and missing-data inference for whole-genome association studies by use of localized haplotype clustering. Am. J. Hum. Genet. 81, 1084-1097 (2007).

58. J. K. Pickrell, J. K. Pritchard, Inference of population splits and mixtures from genomewide allele frequency data. PLoS Genet. 8, e1002967 (2012). 
59. S. Purcell, B. Neale, K. Todd-Brown, L. Thomas, M. A. R. Ferreira, D. Bender, J. Maller, P. Sklar, P. I. W. de Bakker, M. J. Daly, P. C. Sham, PLINK: a tool set for whole-genome association and population-based linkage analyses. Am. J. Hum. Genet. 81, 559-575 (2007).

60. S. Purcell, S. S. Cherny, P. C. Sham, Genetic Power Calculator: design of linkage and association genetic mapping studies of complex traits. Bioinformatics. 19, 149-150 (2003).

61. L. Skotte, T. S. Korneliussen, A. Albrechtsen, Association testing for next-generation sequencing data using score statistics. Genet. Epidemiol. 36, 430-437 (2012).

62. R. Kofler, P. Orozco-terWengel, N. De Maio, R. V. Pandey, V. Nolte, A. Futschik, C. Kosiol, C. Schlötterer, PoPoolation: a toolbox for population genetic analysis of next generation sequencing data from pooled individuals. PLoS One. 6, e15925 (2011).

63. T. D. Schmittgen, K. J. Livak, Analyzing real-time PCR data by the comparative CT method. Nat. Protoc. 3, 1101-1108 (2008).

64. J. L. Feder, X. Xie, J. Rull, S. Velez, A. Forbes, B. Leung, H. Dambroski, K. E. Filchak, M. Aluja, Mayr, Dobzhansky, and Bush and the complexities of sympatric speciation in Rhagoletis. Proc. Natl. Acad. Sci. U. S. A. 102 Suppl, 6573-6580 (2005).

65. J. W. Poelstra, N. Vijay, C. M. Bossu, H. Lantz, B. Ryll, I. Muller, V. Baglione, P. Unneberg, M. Wikelski, M. G. Grabherr, J. B. W. Wolf, The genomic landscape underlying phenotypic integrity in the face of gene flow in crows. Science. 344, 14101414 (2014).

66. A. Stamatakis, RAxML version 8: a tool for phylogenetic analysis and post-analysis of large phylogenies. Bioinformatics. 30, 1312-1313 (2014). 
67. K. Chen, J. W. Wallis, M. D. McLellan, D. E. Larson, J. M. Kalicki, C. S. Pohl, S. D. McGrath, M. C. Wendl, Q. Zhang, D. P. Locke, X. Shi, R. S. Fulton, T. J. Ley, R. K. Wilson, L. Ding, E. R. Mardis, BreakDancer: an algorithm for high-resolution mapping of genomic structural variation. Nat. Methods. 6, 677-681 (2009).

68. X. Huang, A. Madan, CAP3: A DNA sequence assembly program. Genome Res. 9, 868877 (1999).

69. R. E. Green, J. Krause, A. W. Briggs, T. Maricic, U. Stenzel, M. Kircher, N. Patterson, H. Li, W. Zhai, M. H. Y. Fritz, N. F. Hansen, E. Y. Durand, A. S. Malaspinas, J. D. Jensen, T. Marques-Bonet, C. Alkan, K. Prüfer, M. Meyer, H. A. Burbano, J. M. Good, R. Schultz, A. Aximu-Petri, A. Butthof, B. Höber, B. Höffner, M. Siegemund, A. Weihmann, C. Nusbaum, E. S. Lander, C. Russ, N. Novod, J. Affourtit, M. Egholm, C. Verna, P. Rudan, D. Brajkovic, Z. Kucan, I. Gušic, V. B. Doronichev, L. V Golovanova, C. Lalueza-Fox, M. de la Rasilla, J. Fortea, A. Rosas, R. W. Schmitz, P. L. F. Johnson, E. E. Eichler, D. Falush, E. Birney, J. C. Mullikin, M. Slatkin, R. Nielsen, J. Kelso, M. Lachmann, D. Reich, S. Pääbo, A draft sequence of the neandertal genome. Science. 328, 710-722 (2010).

70. J. B. Pease, M. W. Hahn, Detection and polarization of introgression in a five-taxon phylogeny. Syst. Biol. 64, 651-662 (2015).

71. W. Zhang, K. K. Dasmahapatra, J. Mallet, G. R. P. Moreira, M. R. Kronforst, Genomewide introgression among distantly related Heliconius butterfly species. Genome Biol. 17, $25(2016)$.

72. J. H. Gillespie, C. H. Langley, Are evolutionary rates really variable? J. Mol. Evol. 13, 27-34 (1979). 
73. R. N. Gutenkunst, R. D. Hernandez, S. H. Williamson, C. D. Bustamante, Inferring the joint demographic history of multiple populations from multidimensional SNP frequency data. PLoS Genet. 5, e1000695 (2009).

74. G. Ewing, J. Hermisson, MSMS: a coalescent simulation program including

77. P. Cingolani, A. Platts, L. L. Wang, M. Coon, T. Nguyen, L. Wang, S. J. Land, X. Lu, D. M. Ruden, A program for annotating and predicting the effects of single nucleotide polymorphisms, SnpEff: SNPs in the genome of Drosophila melanogaster strain w1118;

76. M. Carneiro, S. Afonso, A. Geraldes, H. Garreau, G. Bolet, S. Boucher, A. Tircazes, G. Queney, M. W. Nachman, N. Ferrand, The genetic structure of domestic rabbits. Mol. Biol. Evol. 28, 1801-1816 (2011). iso-2; iso-3. Fly. 6, 80-92 (2012).

78. A. J. Coffman, P. H. Hsieh, S. Gravel, R. N. Gutenkunst, Computationally efficient composite likelihood statistics for demographic inference. Mol. Biol. Evol. 33, 591-593 (2016).

79. P. Pavlidis, J. D. Jensen, W. Stephan, Searching for footprints of positive selection in whole-genome SNP data from nonequilibrium populations. Genetics. 185, 907-922 (2010). 
403 80. R. Durrett, J. Schweinsberg, A coalescent model for the effect of advantageous mutations 404 on the genealogy of a population. Stoch. Process. their Appl. 115, 1628-1657 (2005).

405 81. M. I. Jensen-Seaman, T. S. Furey, B. A. Payseur, Y. Lu, K. M. Roskin, C.-F. Chen, M. A. 406 Thomas, D. Haussler, H. J. Jacob, Comparative recombination rates in the rat, mouse, and 407 human genomes. Genome Res. 14, 528-538 (2004).

408 82. C. D. Huber, M. DeGiorgio, I. Hellmann, R. Nielsen, Detecting recent selective sweeps 409 while controlling for mutation rate and background selection. Mol. Ecol. 25, 142-156 $410 \quad$ (2016). 
411 Acknowledgments: We thank E. Cheng, K. Garrison, and P. Zevit for assistance with sample

412 collection. We thank R. Bracewell, T. Brekke, M. Carneiro, Z. Clare-Salzler, M. Dean, E.

413 Kopania, M. S. Ferreira, N. Herrera, E. Larson, M. Nachman, B. Payseur, B. Sarver, and

414 members of the NSF EPSCoR UNVEIL network for helpful discussion. R. Bracewell, B. Cole,

415 T. Cosart, L. Farelo, E. Larson, S. Laurent, T. Max, S. Pfeifer, B. Sarver, and K. Zarn provided

416 computational or laboratory support. A. Kumar assisted with the preparation of Fig. 1.

417 Sequencing was performed at the University of Montana Genomics Core, the CIBIO-InBIO

418 University of Porto New-Gen sequencing platform, the University of Oregon Genomics and Cell

419 Characterization Core Facility, the HudsonAlpha Institute for Biotechnology, and Novogene

420 Technology Co. Ltd. Computational resources were provided by the University of Montana

421 Genomics Core and the Vital-IT Center for high-performance computing of the SIB Swiss

422 Institute of Bioinformatics. Funding: National Science Foundation (NSF) Graduate Research

423 Fellowship (DGE-1313190), NSF Doctoral Dissertation Improvement Grant (DGE-1702043),

424 NSF Graduate Research Opportunities Worldwide, Portuguese Fundação para a Ciência e a

425 Tecnologia (FCT) project grant CHANGE (PTDC/BIA-EVF/1624/2014, supported by National

426 Funds), NSF EPSCoR (OIA-1736249), NSF (DEB-0841884), FCT Investigator Grant

427 (IF/00033/2014, supported by POPH-QREN funds from ESF and Portuguese MCTES/FCT),

428 FLAD (Luso-American Development Foundation; PORTUGAL - U.S. Research Networks

429 Program), the Drollinger-Dial Foundation, American Society of Mammalogists Grant-in-aid of

430 Research, Swiss Government Excellence Scholarship, and European Union’s Seventh

431 Framework Programme (CIBIO New-Gen sequencing platform; grant agreement 286431).

432 Author contributions: M.R.J., L.S.M., P.C.A., J.D.J., J.M.F., and J.M.G. designed the study.

433 J.M.G. coordinated the study. M.R.J, C.M.C., J.A., and D.J.R.L. generated data. J.A. and F.M.J. 
434 helped develop the exome capture experiments. M.R.J. performed data analyses under the 435 guidance of J.M.G., J.M.F., and J.D.J. M.R.J. and J.M.G. wrote the paper with input from the 436 other authors. All authors approved the manuscript before submission. Competing interests:

437 None declared. Data and materials availability: Original sequence data are available in the 438 Sequence Read Archive (www.ncbi.nlm.nih.gov/sra) under BioProject PRJNA420081 (accession 439 numbers SAMN08146448- SAMN08146534). Previously generated whole genome sequence 440 data of snowshoe hare (SAMN02782769, SAMN07526959) and mountain hare 441 (SAMN07526960) are also available in the Sequence Read Archive. 


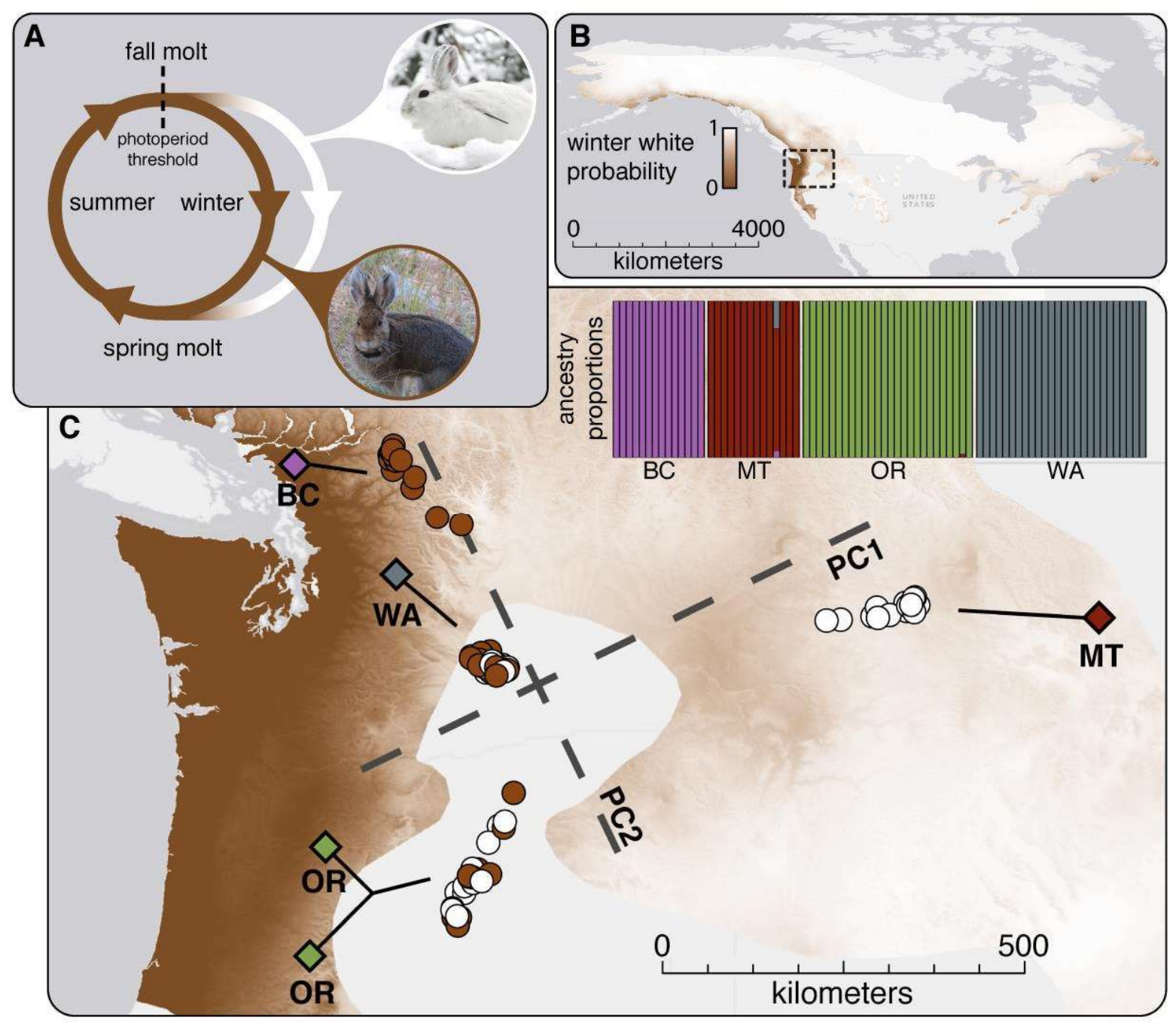

Fig. 1. Winter coat color polymorphism and population structure in snowshoe hares. (A)

444 Alternative winter color morphs in snowshoe hares. (B) The modeled range-wide probability of

445 winter-white coats, adapted from (7). (C) Principle components (PC1 - 7.42\%, PC2 - 5.27\%;

446 coat color represented as brown/white circles) and population ancestry plots of 38,694 unlinked

447 SNPs derived from 80 exomes sampled from five localities (colored diamonds) overlaid on the 448 probability of winter-white coats in the Pacific Northwest. 


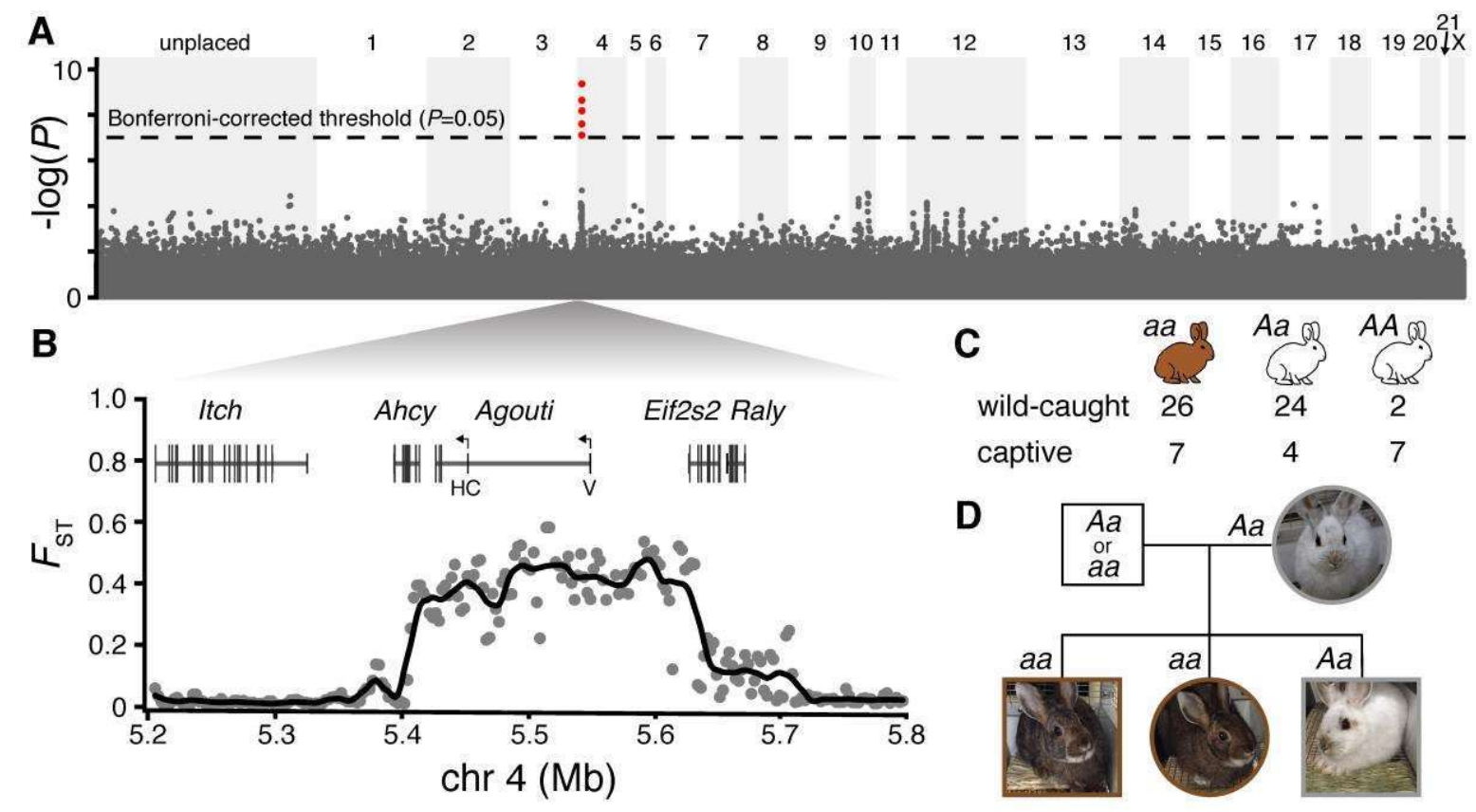

450 Fig. 2. The genetic basis of winter coat color polymorphism. (A) Exome SNP associations (-

$451 \log _{10}$ of $P$-values, assuming dominant minor allele, 513,812 SNPs) for polymorphic zone

452 individuals. Red points above dashed line exceed the Bonferroni-corrected threshold of $P=0.05$.

453 (B) Gene structure across the associated interval and alternative Agouti transcription start sites

454 (arrows) corresponding to hair-cycle (HC) and ventral (V) 5' UTRs. Sliding window averages of

$455 \quad F_{\mathrm{ST}}(5 \mathrm{~kb}$ with $2.5 \mathrm{~kb}$ step) between winter-white and winter-brown individuals with low-

456 coverage whole genomes $(15,173,804$ SNPs). (C) Dominance of winter coat color inferred from

457 Agouti genotypes of wild (OR and WA; Hardy-Weinberg $\chi^{2}=1.6, P=0.21$ ) and captive (WA and

458 MT) hares. (D) Pedigree and genotypes of a mixed phenotype family (paternal genotype is

459 unknown, but inferred to carry the $a$ allele). 
A

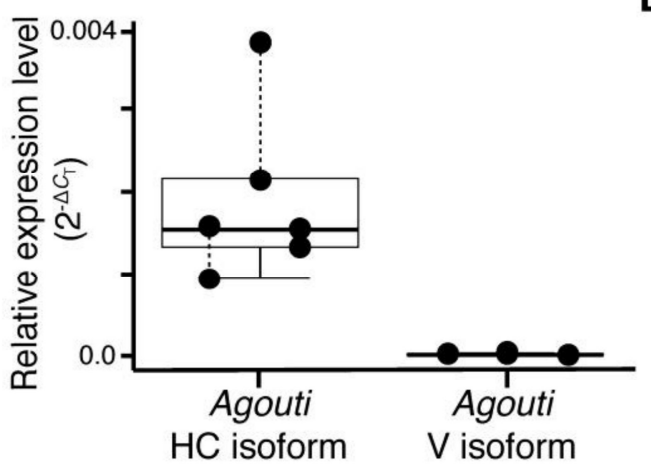

B

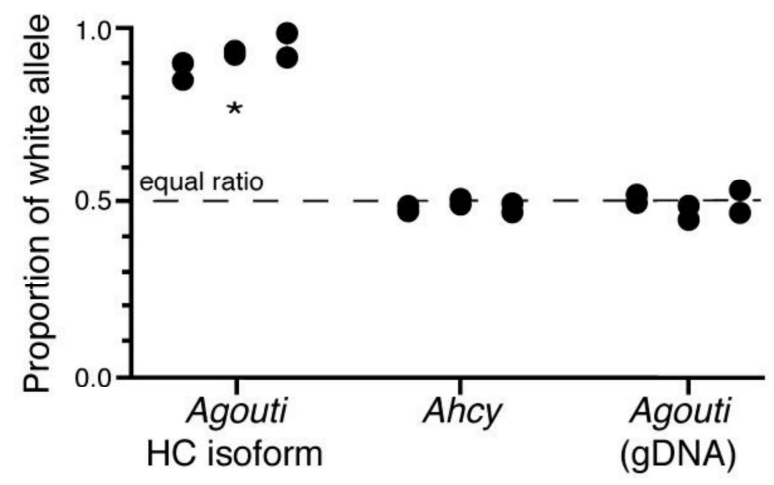

Fig. 3. Agouti expression in snowshoe hares during autumn molts. (A) The relative

expression level (2- ${ }^{-\Delta C_{\mathrm{T}}}$, normalized to Gapdh) of hair-cycle (HC) and ventral (V) Agouti isoforms

463 in molting skin of winter-white $(A a)$ snowshoe hares. (B) Relative abundance of the winter-white

464 allele in the same skin samples for Agouti hair-cycle transcripts, Ahcy transcripts, and Agouti

465 genomic DNA. White allele proportions were significantly elevated in Agouti transcripts

466 compared to Ahcy transcripts and Agouti genomic DNA ( $P<0.00001$, Student's t-test). Pairs of

467 points represent technical replicates. 
black-tailed jackrabbit

2. mountain hare European rabbit
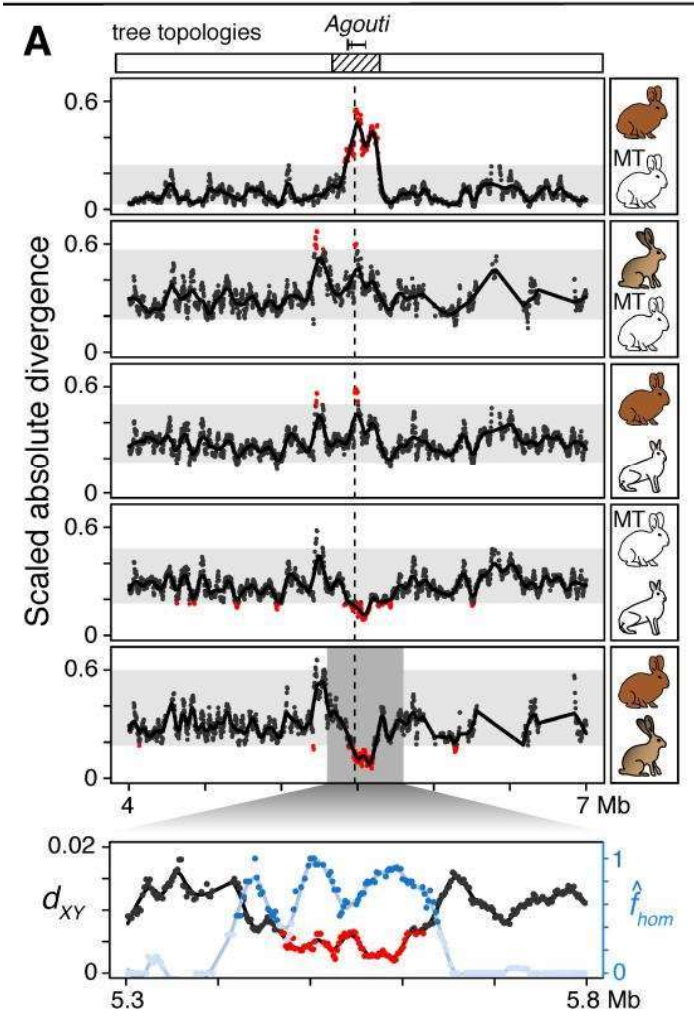
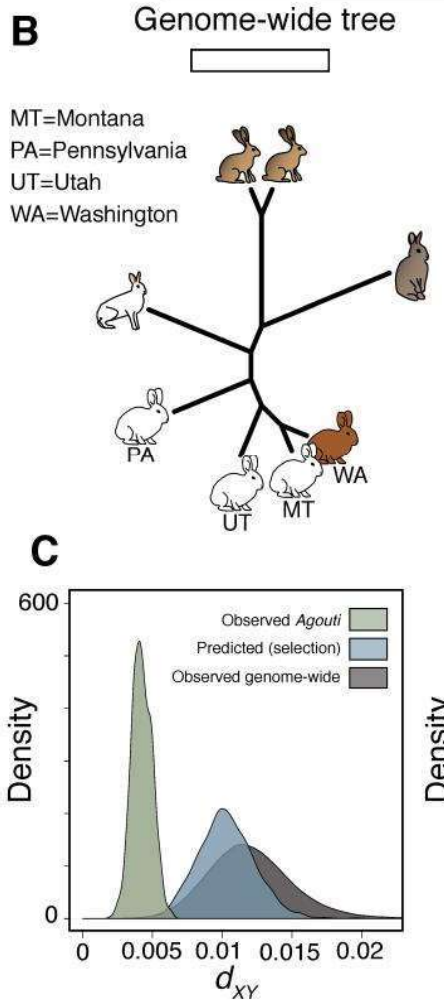

Local Agouti tree VIIIIIIII

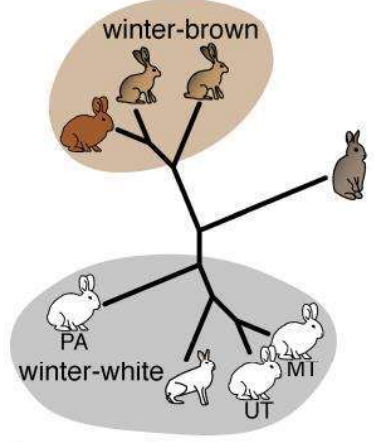

D

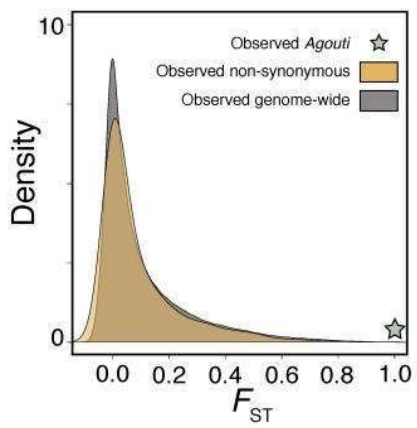

Fig. 4. The evolution of winter coat color alleles in hares and jackrabbits. (A) Estimated tree topologies across the Agouti region (top, see 4B). Mutation-scaled absolute genetic divergence in $20 \mathrm{~kb}$ sliding windows for pairs of individuals (dashed line indicates location of candidate insertion-deletion mutations). Gray rectangles represent $99.8 \%$ bootstrap quantiles and red points are windows with one-tailed $P<0.001$. Bottom plot shows a finer scale of absolute divergence in black ( $d_{X Y}$, red points with one-tailed $\left.P<0.001\right)$ and the fraction of introgression in blue $\left(\hat{f}_{\text {hom }}\right.$, dark blue points with z-score $>4$ ) between black-tailed jackrabbits and the WA winter-brown snowshoe hare. (B) The most common genome-wide topology (white) and the local Agouti

477 topology (hatched; rabbit outgroup). (C) Distributions of $d_{X Y}$ between the winter-brown

478 snowshoe hare and black-tailed jackrabbits genome-wide (gray), at Agouti (green), and under

479 simulations of strong ancestral selection (blue). (D) Distributions of SNP $F_{\text {ST }}$ values between BC 
480 (monomorphic winter-brown) and MT (monomorphic winter-white) hares genome-wide (gray)

481 and for non-synonymous SNPs (yellow). $F_{\mathrm{ST}}=1$ at a diagnostic Agouti SNP, indicated with a 482 green star. 